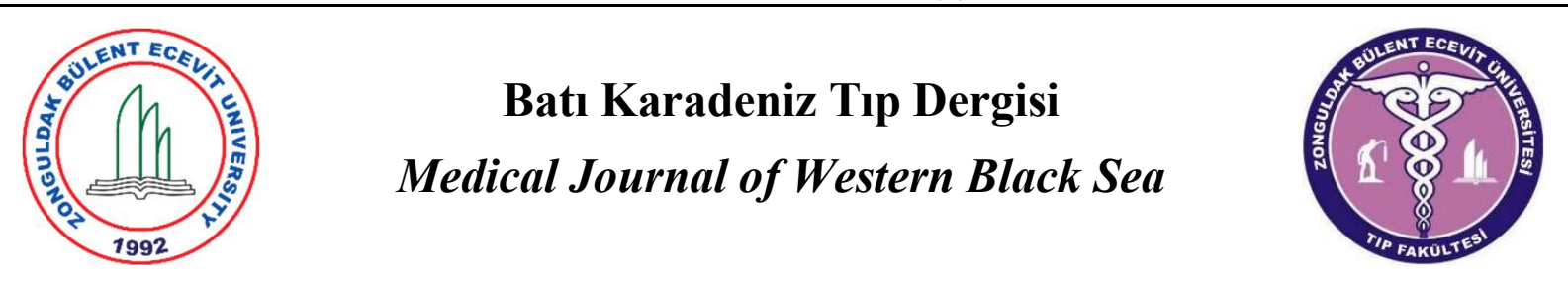

Araştırma Makalesi

Doi: $10.29058 / \mathrm{mjwbs} .2019 .1 .2$

\title{
Zonguldak Kadın Doğum Ve Çocuk Hastalıkları Hastanesine İsteğe Bağlı Kürtaj Nedeniyle Başvuran Gebelerin Aile Planlaması Pratikleri Açısından Değerlendirilmesi
}

\author{
İsa Şükrü Öz ${ }^{\text {a }}$, Anı1 Turhan Çakır ${ }^{\text {a }}$, Burak Ün ${ }^{\text {a }}$, Besim Haluk Bacanakgil ${ }^{\text {b }}$ \\ ${ }^{a}$ Zonguldak Kadın Doğum ve Çocuk Hastalıkları Hastanesi, Zonguldak, Türkiye \\ ${ }^{b}$ İstanbul Eğitim ve Araştırma Hastanesi, İstanbul, Türkiye
}

ORCİD : İsa Şükrü Öz 000000018849 2705, Anıl turhan Çakır 000000017976 4123, Burak Ün 0000000288857062 , Besim Haluk Bacanakgil 0000000247237297

\begin{tabular}{|c|c|}
\hline $\begin{array}{l}\text { M A K A L E } \\
\text { B İ L G I S İ }\end{array}$ & \multirow{2}{*}{$\begin{array}{l}\text { Ö Z } \\
\text { Amaç: Hastanemize isteğe bağlı gebelik sonlandırması için }\end{array}$} \\
\hline Gönderilme Tarihi: & \\
\hline 5.12 .2018 & başvuran gebelerin aile planlaması açısından değerlendirilmesidir. \\
\hline Revizyon: & \multirow{16}{*}{ 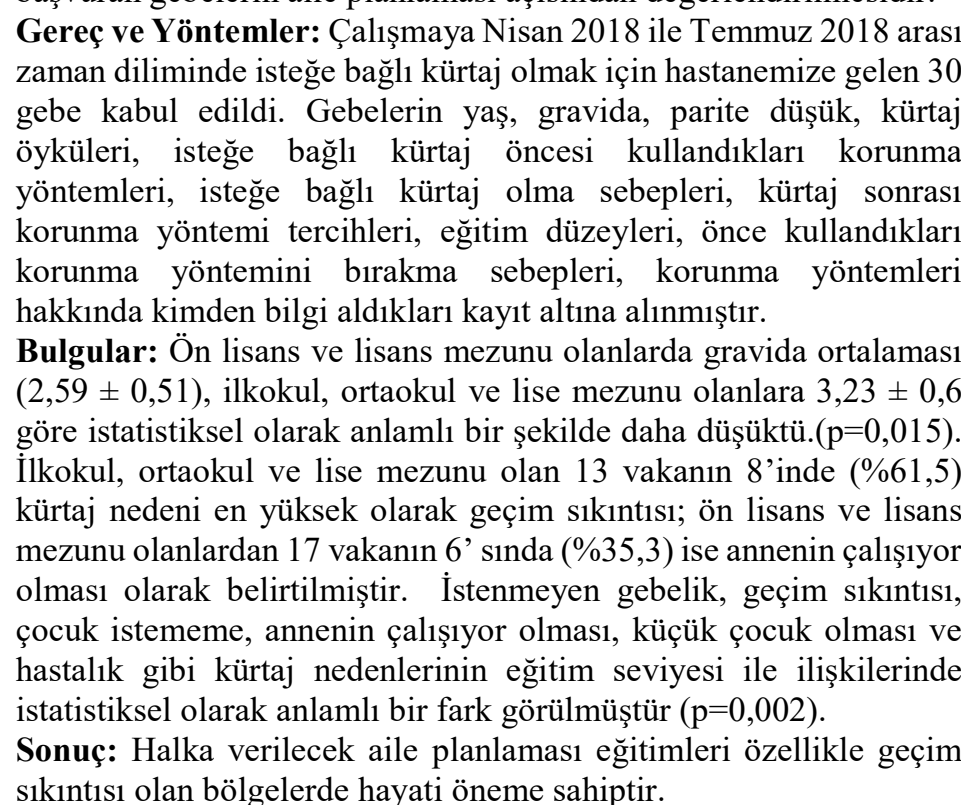 } \\
\hline 27.04.2019 & \\
\hline Kabul: & \\
\hline 28.04.2019 & \\
\hline Sorumlu Yazar: & \\
\hline İsa şükrü Öz & \\
\hline isaoz80@gmail.com & \\
\hline Anahtar Kelimeler: & \\
\hline Isteğe bağll kürtaj, Aile & \\
\hline Planlaması, Korunma Yöntemleri & \\
\hline & \\
\hline & \\
\hline & \\
\hline & \\
\hline & \\
\hline & \\
\hline
\end{tabular}




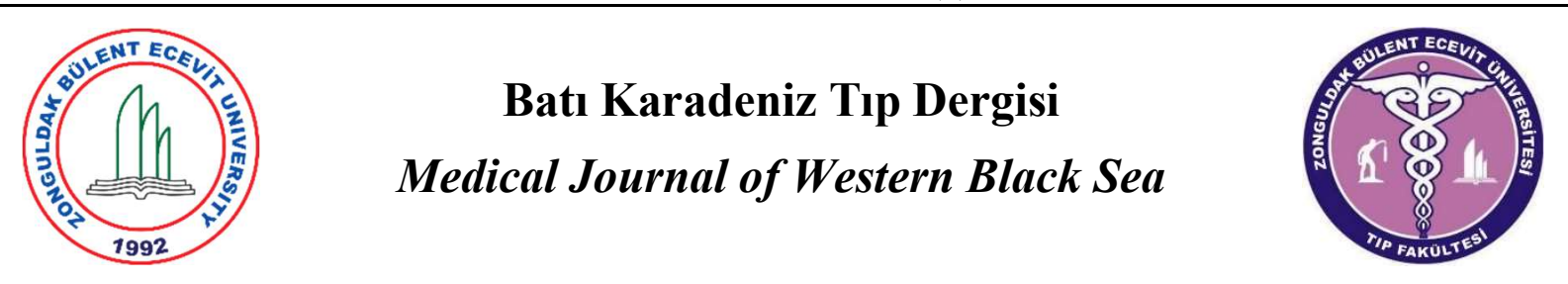

Research Article

Doi: $10.29058 / \mathrm{mjwbs} .2019 .1 .2$

\section{Evaluation In Terms Of Family Planning Practices For Legal Abortion Who Consult Zonguldak Pregnant And Child Diseases Hospital}

İsa Şükrü Öz ${ }^{\text {a }}$, Anı1 Turhan Çakır a ${ }^{\text {a }}$ Burak Ün ${ }^{\text {a }}$, Besim Haluk Bacanakgil ${ }^{\text {b }}$

${ }^{a}$ Zonguldak Obstetrics and Gynecology Hospital, Zonguldak, Turkey

${ }^{b}$ Istanbul Education and Research Hospital, İstanbul, Turkey

\begin{tabular}{l} 
A R T I C L E \\
I N F O R M A T I O N \\
\hline Date of Submission \\
5.12 .2018 \\
Revision: \\
27.04 .2019 \\
Accepted: \\
28.04 .2019 \\
Correspondence Author: \\
İsa şükrü Öz \\
isaoz80@gmail.com \\
\hline Key Words: \\
Optional abortion, Family \\
Planning, Prevention Methods
\end{tabular}

\begin{abstract}
A B S T R A C T
Aim: It is the evaluation of the pregnancies applying for termination
of pregnancy to my hospital in terms of family planning.
Material and Methods: During the period from April 2018 to July
2018,30 pregnant women who were admitted to our hospital to
receive an optional abortion were admitted to the study. Pregnant
women were recorded for age, gravida, low parity, abortion stories,
prevention methods for abortion, reasons for requesting abortion,
prevention methods after abortion, education levels, reasons for
dropping the protection method they used first. The inter-variable
comparisons were made using the Fisher's Exact Test for categorical
data and Mann Whitney-U test for numerical data.
Results: The gravida average ( $2,59 \pm 0,51)$ was significantly lower
in those with undergraduate and undergraduate degrees and $3,23 \pm$
0,6 in the ones with primary, secondary and high school graduates
(p=0,015). 8 out of 13 cases ( $61.5 \%)$ of elementary school, junior
high school and high school graduates had the highest abortion
cause. (35,3\%) of those who have undergraduate and graduate degree
are working as mother. A statistically significant difference was
found in relation to the education level of the causes of unplanned
pregnancy, loneliness, unwanted children, maternal work, having
children, and illness (p=0,002).
\end{abstract}

Conclusion: Family planning training to be given to the public has vital importance especially in poor regions. 


\section{Giriş}

Günümüzde ülkemizde aile planlaması denilince akla gelen çocuk sayısının kısıtlanma yöntemleridir. Fakat aile planlanması esas olarak çiftlerin istenen sayıda, istenen aralıklarla çocuk sahibi olmalarını planlamaya yarayan sistemler topluluğudur. Geçim sıkıntısının yoğun olarak yaşandığı Türkiye gibi ülkelerde aile planlaması sistemleri sayesinde ailelerin geçindirebilecekleri, gelecek sağlayabilecekleri kadar çocuk sahibi olmaları, gebelik aralıklarının bunlara göre düzenlenmesi aile ve toplum sağlı̆̆ açısından önem arz etmektedir. Bunlara ek olarak aile planlaması sistemleri ülkelerin öz kaynaklarının efektif kullanılması bağlamında da önemlidir (1). Geniş açıdan bakıldığında aile planlaması demek çocuk sahibi olmanın kısıtlanması demek değil, gebelik süreleri aralarının bilinçli olarak kararlaştırılması anlamına gelir. Olaya halk sağlığı açısından bakıldığında ise istenmeyen gebelikler sosyolojik olarak toplum sağlığı sorunudur (2). Dünya Sağlık Örgütü verilerine göre her yıl ortalama seksen dört milyon kişide istenmeyen gebelik görülmektedir (3). İstenmeyen gebeliklerin büyük çoğunluğu isteğe bağlı kürtaj ile sonuçlanmaktadır. Bu kürtajlar sonucunda bazı anneler hayatlarını kayıp edebilmeye varabilecek düzeyde çeşitli sağlık sorunları yaşayabilmektedirler. Yine dünya sağlığı örgütünün verilerine göre her y1l istenmeyen gebelik ve güvensiz düşük sonrası 17 bin kadın hayatını kayıp edebilmektedir (3). Ülkemizde ise anne adayı istenmeyen bir gebelikle karşılaştı̆ğnda kendini toplumsal olarak bir baskı altında hissetmekte ve kürtaj olmaya veya kürtaj oldurtulmaya zorlanmaktadır. Hala ülkemizde uygun olmayan denetimsiz ortamlarda yapılan kürtajlar önemli bir üreme sağlığı sorunu olarak karşımıza çıkmaktadır (4). $\mathrm{Bu}$ veriler göz önüne alındığında çiftlerin gebelikten korunma yöntemleri hakkında bilgi sahibi olmaları, aile planlaması uygulamalarının etkin olarak kullanımının sağlanması, anne sağlığı açısından önemlidir. 1983 yılında ülkemizde çıkan yasayla istenmeyen gebeliğe bağlı 10. gebelik haftasına kadar kürtaj legal hale getirilmiştir (5). Bu durum birçok aile tarafından benimsenmesine rağmen hala ülkemizde isteğe bağlı kürtaj bir aile planlaması yöntemi olarak görülememektedir. Tüm bu bahsedilenlerden yola çıkılarak önem kazanan ve üzerinde ehemmiyetle durulması gereken durum, isteğe bağlı kürtaj sonrası ailenin şartları göz önüne alınarak ve ailenin şartlarına uygun olacak şekilde korunma yöntemleri hakkında ailenin bilgi düzeyini artırmak olmalıdır. Bu konuda isteğe bağlı kürtaj için hastanelere başvuran kişilere aile planlaması ile alakalı danışmanlık hizmetinin verilmesi ülkemizdeki üreme sağlığı bağlamında hayati önem taşımaktadır. Çalışmamızda Zonguldak Kadın Doğum ve Çocuk Hastalıkları Hastanesi'ne isteğe bağlı kürtaj için başvuran hastaların aile planlaması açısından değerlendirmesini gerçekleştirdik.

\section{Gereç ve Yöntemler}

Çalışmamıza Nisan 2018 ile Temmuz 2018 tarihleri arasında, 10 haftanın altında gebelik yaşları olan, isteğe bağlı kürtaj olmak üzere hastanemize başvuran anne adayları alınmıştır. Toplam 30 anne adayı çalışmaya katılmıştır. Gebelik haftaları yasal kürtaj sınırının üzerinde olan ve medikal sebeplerle kürtaj olması gereken kişiler çalışmaya dahil edilmemiştir. İsteğe bağlı kürtaj olmak için gelen gebeler ve eşleri boş bir servis odasına alınmış ve sorular yüz yüze sorulmuştur. Gebelerin yaş, gravida, parite, durumları, düşük ve kürtaj geçmişleri, eğitim düzeyleri, daha önce kullandıkları korunma yöntemleri, isteğe bağlı kürtaj nedenleri, daha önce kullandıkları korunma yöntemlerini bırakma sebepleri, daha önce kullandıkları korunma yöntemi hakkında nereden bilgi aldıkları, kürtaj sonras1 kullanabilecekleri korunma yöntemi tercihleri, ülkemizde sık kullanılmayan korunma yöntemlerinden olan spermisit, diyafragma, servikal başlık hakkındaki bilgi düzeyleri ile acil kontrasepsiyon hakkındaki bilgi düzeyleri değerlendirilerek kayıt altına alınmıştır.

Çalışma Helsinki Deklerasyonu Prensipleri'ne uygun olarak yapılmıştır. Zonguldak Bülent Ecevit Üniversitesi İnsan Araştırmaları Etik Kurulu'ndan ve çalışmaya katılmış insanlardan "Bilgilendirilmiş Olur" alınmıştır.

İstatistiksel analiz için SPSS 22.0 for Windows programı kullanıldı. Tanımlayıcı istatistikler sayısal değişkenler için minimum maksimum değerler, normal dağılan verilerde ortalama ve standart sapma ile normal dağılmayan verilerde ortanca (minimum maksimum) şeklinde, nitel değişkenler için ise sayı ve yüzde olarak verildi. Gruplar aras1 karşılaştırmalar niteliksel veriler için Fisher's Exact Test testi ve niceliksel veriler için de veriler Kolmogorov-Smirnov testi sonucuna göre normal dağılmadığı için Mann Whitney-U testi ile yapıldı. $p$ değeri 0.05 'ten küçük ise sonuç istatistiksel olarak anlamlı kabul edildi.

\section{Bulgular}

Çalışma grubunda yer alan toplam 30 vakanın yaş ortalaması $32,33 \pm 3,17$ idi. İlkokul, ortaokul ve lise mezunu olan 13 vakanın ortalama yaşı 33,23 \pm 
3,09, ön lisans ve lisans mezunu 17 vakanın yaş ortalamas1 ise 31,65 $\pm 3,14$ idi. Eğitim seviyesine göre çalışma grubundaki vakalar arasında yaş ortalamaları bakımından istatistiksel olarak anlamlı bir fark görülmedi $(\mathrm{p}=0,270)$ (Tablo 1).

Ön lisans ve lisans mezunu olanlarda gravida ortalaması $(2,59 \pm 0,51)$, ilkokul, ortaokul ve lise mezunu olanlara 3,23 $\pm 0,6$ göre istatistiksel olarak anlamlı bir şekilde daha düşüktü. $p=0,015$ ). (Tablo 1)

İlkokul, ortaokul ve lise mezunu olan 13 vakanın 8 'inde $(\% 61,5)$ kürtaj nedeni en yüksek olarak geçim sıkıntısı; ön lisans ve lisans mezunu olanlardan 6 vakada $(\% 35,3)$ ise annenin çalışıyor olması olarak belirtilmiştir.

İstenmeyen gebelik, geçim sıkıntısı, çocuk istememe, annenin çalışıyor olması, küçük çocuk olması ve hastalık gibi kürtaj nedenlerinin eğitim seviyesi ile ilişkilerinde istatistiksel olarak anlamlı bir fark görülmüştür ( $\mathrm{p}=0,002)$ (Tablo 2).

İlkokul, ortaokul ve lise mezunu olanlar ile ön lisans ve lisans mezunu olanlar arasında daha önce kullandığı takvim, geri çekilme, kondom, ria, oks, iğne ve minipil gibi kontrasepsiyon yöntemleri bakımından istatistiksel olarak anlamlı bir fark görülmemiştir ( $\mathrm{p}=0,603)$ (Tablo 3).

Çalışmaya katılan kişilerde isteğe bağlı kürtaj olmadan önce kullandıkları korunma yöntemleri sorgulandığında en sık ile oral kontraseptif kullanımı öne çıkmaktadır. Daha önce kullanılan kontrasepsiyon yöntemi ise en sık kanamaya bağlı olarak bırakılmıştır. Çalışmaya katılanların \%93,3’ ü spermisit, diyafram ve servikal başlık hakkında bilgi sahibi değildirler. Çalışmaya katılanların \%60’ nın ise acil kontrasepsiyon hakkında bilgi sahibi oldukları görülmüştür. (Tablo 4).

Tablo 1: Çalışma Grubunun Yaş, Gravida ve Parite Değerlerinin Karşılaştırılması

\begin{tabular}{|c|c|c|c|c|c|c|c|c|c|c|}
\hline & \multicolumn{3}{|c|}{$\begin{array}{c}\text { Tüm Vakalar } \\
\mathbf{n}=\mathbf{3 0}\end{array}$} & \multicolumn{3}{|c|}{$\begin{array}{c}\text { İlkokul, Ortaokul ve Lise } \\
\text { Mezunu Olanlar } \\
\text { n=13 }\end{array}$} & \multicolumn{3}{|c|}{$\begin{array}{l}\text { Ön lisans ve Lisans } \\
\text { Mezunu Olanlar } \\
n=17\end{array}$} & \multirow[t]{2}{*}{$\mathbf{p}$} \\
\hline & $\begin{array}{l}\text { Min- } \\
\text { Maks }\end{array}$ & $\bar{x} \pm \mathrm{Ss}$ & Ortanca & $\begin{array}{l}\text { Min- } \\
\text { Maks }\end{array}$ & $\bar{x} \pm \mathrm{Ss}$ & Ortanca & $\begin{array}{l}\text { Min- } \\
\text { Maks }\end{array}$ & $\bar{x} \pm \mathrm{Ss}$ & Ortanca & \\
\hline Yaş & $27-38$ & $\begin{array}{l}32,33 \\
\pm 3,17\end{array}$ & 32 & $29-38$ & $\begin{array}{l}33,23 \\
\pm 3,09\end{array}$ & 32 & $27-36$ & $\begin{array}{l}31,65 \\
\pm 3,14\end{array}$ & 32 & 0,270 \\
\hline Gravida & $2-4$ & $\begin{array}{c}2,87 \\
\pm 0,63\end{array}$ & 3 & $2-4$ & $\begin{array}{l}3,23 \\
\pm 0,6\end{array}$ & 3 & $2-3$ & $\begin{array}{c}2,59 \\
\pm 0,51\end{array}$ & 3 & $0,015 *$ \\
\hline Parite & $1-3$ & $\begin{array}{c}1,37 \\
\pm 0,56\end{array}$ & 1 & $1-3$ & $\begin{array}{c}1,54 \\
\pm 0,66\end{array}$ & 1 & $1-2$ & $\begin{array}{c}1,24 \\
\pm 0,44\end{array}$ & 1 & 0,298 \\
\hline
\end{tabular}

Yaş için Mann Whitney U, Gravida ve Parite için ise Pearson Pearson Ki-kare Testi kullanılmıştır. 
Tablo 2: Kürtaj Nedeni

\begin{tabular}{|c|c|c|c|c|c|}
\hline Nedenler & İlko & $\begin{array}{l}\text { ve lise mezunları } \\
13\end{array}$ & \multicolumn{2}{|c|}{$\begin{array}{l}\text { Ön lisans ve lisans mezunları } \\
\mathbf{n}=17\end{array}$} & $\mathbf{p}$ \\
\hline $\begin{array}{l}\text { İstenmeyen } \\
\text { gebelik }\end{array}$ & 0 & $0,0 \%$ & 3 & $17,6 \%$ & \\
\hline Geçim sıkıntısı & 8 & $61,5 \%$ & 0 & $0,0 \%$ & \\
\hline Çocuk istememe & 4 & $30,8 \%$ & 4 & $23,5 \%$ & \\
\hline $\begin{array}{c}\text { Annenin } \\
\text { çalışıyor olması }\end{array}$ & 0 & $0,0 \%$ & 6 & $35,3 \%$ & \\
\hline $\begin{array}{l}\text { Küçük çocuk } \\
\text { olması }\end{array}$ & 1 & $7,7 \%$ & 3 & $17,6 \%$ & \\
\hline Hastalık & 0 & $0,0 \%$ & 1 & $5,9 \%$ & \\
\hline
\end{tabular}

Fisher's Exact Test kullanılmıştır.

Tablo 3: Daha Önce Kullandığı Kontrasepsiyon Yöntemi

\begin{tabular}{|c|c|c|c|c|c|}
\hline Yöntem & \multicolumn{2}{|c|}{$\begin{array}{l}\text { İlkokul, ortaokul ve lise mezunları } \\
n=13\end{array}$} & \multicolumn{2}{|c|}{$\begin{array}{l}\text { Ön lisans ve lisans mezunları } \\
\qquad \mathbf{n}=17\end{array}$} & $\mathbf{p}$ \\
\hline Takvim & 1 & $7,7 \%$ & 1 & $5,9 \%$ & \multirow{7}{*}{0,672} \\
\hline Geri çekilme & 2 & $15,4 \%$ & 2 & $11,8 \%$ & \\
\hline Kondom & 0 & $0,0 \%$ & 3 & $17,6 \%$ & \\
\hline Ria & 3 & $23,1 \%$ & 1 & $5,9 \%$ & \\
\hline Oks & 4 & $30,8 \%$ & 4 & $23,5 \%$ & \\
\hline İğne & 2 & $15,4 \%$ & 4 & $23,5 \%$ & \\
\hline Minipil & 1 & $7,7 \%$ & 2 & $11,8 \%$ & \\
\hline
\end{tabular}

Fisher’s Exact Test kullanılmıştır. 
Tablo 4: Olgulara ilişkin bilgilerin dağılımları

\begin{tabular}{|c|c|c|c|}
\hline & & $\mathbf{n}$ & $\%$ \\
\hline \multirow{5}{*}{ Ĕgitim Durumu } & İlkokul & 5 & 16,7 \\
\hline & Ortaokul & 3 & 10,0 \\
\hline & Lise & 5 & 16,7 \\
\hline & Ön lisans & 9 & 30,0 \\
\hline & Lisans & 8 & 26,7 \\
\hline \multirow{6}{*}{ Kürtaj Nedeni } & İstenmeyen gebelik & 3 & 10,0 \\
\hline & Geçim sıkıntısı & 8 & 26,7 \\
\hline & Çocuk istememe & 8 & 26,7 \\
\hline & $\begin{array}{l}\text { Annenin çalışıyor } \\
\text { olması }\end{array}$ & 6 & 20,0 \\
\hline & Küçük çocuk olması & 4 & 13,3 \\
\hline & Hastalık & 1 & 3,3 \\
\hline \multirow{7}{*}{$\begin{array}{c}\text { Daha Önce Kullandığı Kontrasepsiyon } \\
\text { Yöntemi }\end{array}$} & Takvim & 2 & 6,7 \\
\hline & Geri çekilme & 4 & 13,3 \\
\hline & Kondom & 3 & 10,0 \\
\hline & Ria & 4 & 13,3 \\
\hline & Oks & 8 & 26,7 \\
\hline & İğne & 6 & 20,0 \\
\hline & Minipil & 3 & 10,0 \\
\hline \multirow{8}{*}{$\begin{array}{c}\text { Daha önce kullandığı kontrasepsiyon } \\
\text { yöntemini bırakma sebebi }\end{array}$} & Uyum sağlayamama & 3 & 10,0 \\
\hline & Kanama & 9 & 30,0 \\
\hline & Ağr1 yapması & 1 & 3,3 \\
\hline & İstenmeyen gebelik & 3 & 10,0 \\
\hline & Eşinin istememesi & 2 & 6,7 \\
\hline & Hastalık & 2 & 6,7 \\
\hline & Bulantı kusma & 2 & 6,7 \\
\hline & $\begin{array}{l}\text { Kendi isteğiyle } \\
\text { birakma }\end{array}$ & 8 & 26,7 \\
\hline \multirow{7}{*}{$\begin{array}{l}\text { Daha önce kullandığı kontrasepsiyon } \\
\text { yöntemi hakkında bilgi aldığı kişi }\end{array}$} & Ebe & 7 & 23,3 \\
\hline & Arkadaşı & 3 & 10,0 \\
\hline & Eşi & 1 & 3,3 \\
\hline & Doktor & 8 & 26,7 \\
\hline & Eczaci & 6 & 20,0 \\
\hline & Internet & 2 & 6,7 \\
\hline & Hiç kimse & 3 & 10,0 \\
\hline \multirow{5}{*}{$\begin{array}{l}\text { Daha sonraki kullanmak isteği } \\
\text { kontrasepsiyon tercihi }\end{array}$} & Tüp ligasyonu & 6 & 20,0 \\
\hline & Ria & 13 & 43,3 \\
\hline & Geri çekme & 5 & 16,7 \\
\hline & Kondom & 4 & 13,3 \\
\hline & Oks & 2 & 6,7 \\
\hline \multirow{2}{*}{$\begin{array}{c}\text { Servikal başlık, diyafragma, spermisit } \\
\text { hakkında bilgi sahibi olma }\end{array}$} & Yok & 28 & 93,3 \\
\hline & Var & 2 & 6,7 \\
\hline \multirow{2}{*}{$\begin{array}{c}\text { Acil kontrasepsiyon hakkında bilgi sahibi } \\
\text { olma }\end{array}$} & Yok & 12 & 40,0 \\
\hline & Var & 18 & 60,0 \\
\hline
\end{tabular}




\section{Tartışma}

Gebe kaldığını öğrenen her kadının gebeliği doğumla sonlanmamaktadır. Çeşitli sebeplerle anne adayları isteğe balı olarak kürtaj olmak zorunda kalabilmektedirler. İstenmeyen gebelikler ülkemiz için önemli bir üreme sağlı̆̆ problemi olarak karşımıza çıkmaktadır. Ülkemizin nüfusu arttıkça, ülke öz kaynaklarının kullanımında kişi başına düşen pay azalmakta bu durum mali açıdan çeşitli olumsuzluklara yol açmakta ve kişilerin fakirlik düzeyi artmaktadır (6). Ülke ekonomisinin etkin kullanımı ve toplum sağlığı gibi konularla birlikte aile planlaması sosyolojik olarak da önem arz etmektedir. Ülkemizde devlet kurumları tarafindan yapılan geniş kapsamlı ulusal bir çalışmada, ülkemizde yaşayan kadınların üçte ikisinden fazlasının hayatlarının belirli bir döneminde korunma yöntemi kullandıkları görülmüştür (7). Aynı çalışmaya göre ülkemizdeki kadınların toplam doğurganlık hızı 2.2 dir. Ve eğitim seviyesi ile doğurma hızı arasında ters orantı vardır (7). Aynı şekilde bizim yaptığımız çalışmada da eğitim düzeyi ile gravida ve parite ortalamalarına bakıldığında katılımcıların eğitim düzeyleri arttıkça gravida ve parite ortalamalarımın azaldığı görülmektedir. Yine ülkemizde yapılan başka bir çalışmada kadınlar arasında kullanılan en yaygın korunma yöntemleri sırasıyla rahim içi araç, geri çekme yöntemi ve kondom olarak gösterilmiştir (8). Bu çalışmadan farklı olarak ulusal bazda en s1k görülen korunma yöntemi geri çekme yöntemidir (9-11). Bizim yaptığımız çalışmada ise en yaygın korunma yöntemleri sırasıyla oral kontraseptifler, iğne ve geri çekme yöntemidir. Çalışmamızda isteğe bağlı kürtaj için hastanemize gelen kişilere sorulan 'Neden kürtaj olmak istiyorsun?' sorusuna ilkokul, ortaokul, lise mezunlarında alınan en sık cevap 'geçim sıkıntısı' olurken lisans ve ön lisans mezunlarında 'annenin çalışıyor olması' olmuştur. Ulusal yapılan farklı çalışmalarda ise yine geçim sıkıntısı en yaygın cevap olurken ikinci yaygın cevap olarak çocuk istememe olmuştur (12,13). Çalışmamızda kürtaj sebeplerine aldığımız cevapların eğitim düzeyi ile kıyası yapıldığında 'çocuk istememe', 'annenin çalışıyor olması durumu', 'hastalık mevcudiyeti', 'küçük çocuk olması' cevaplarının eğitim düzeyinin artması ile doğru orantılı olarak değiştiği sonucuna vardık. Kişilerin kürtaj sonrası korunma tercihlerine bakıldığında en sık rahim içi araç tercihi görülürken, ikinci sıklıkla tüp ligasyonu görülmektedir. Şaşırtıcı olarak kürtaj öncesi en sık görülen korunma yöntemi tercihi olan oral kontraseptifler kürtaj sonrası sıklıkla tercih edilmemektedir. 'Kürtaj öncesi korunma yöntemleri hakkında kimden bilgi aldınız?' sorusuna en sik alınan cevap 'doktor' olurken, bu soruya 'internetten bilgi aldım' veya 'hiç kimseden bilgi almadım kafama göre başladım' cevaplarıda alınmıştır. Burada akla gelen sorulardan birisi doktor ve ebe dişındaki kişilerin üreme sağlığı konusunda ne kadar bilgili oldukları, hastalara verilen bilgilerin ne kadar sağlıklı olduğudur. Bu durum aslında bazı konularda halkımızın ne kadar bilinçsiz davrandığının göstergesidir. Budak ve ark (14) yaptı̆̆ı çalışmada spermisit, diyafram ve servikal başlık kullanımı hakkında kişilerin eğitim düzeyleri arttıkça bu yöntemler hakkında bilgi sahibi olma oranlarının arttığını göstermişlerdir. Bizim çalışmamızda ise katılımcıların \% 93.3 ü servikal başlık, diyafram, spermisit hakkında bilgi sahibi olmadıklarını söylemişlerdir. Aynı şekilde Gılıç ve ark. (15) hastaların entelektüel seviyeleri arttıkça korunma yöntemi tercihlerini uzman kişilerce beraber yaparak şekillendirdiklerini göstermişlerdir.

Konu ile alakalı Zonguldak bölgesinde daha önce yapılan bir çalışma bulunmamaktadır. Zonguldak bölgesindeki aile planlaması değerlendirmesi açısından çalışmamızın önemli olduğunu düşünmekteyiz. Fakat çalışmadaki hasta sayımızın azlığı çalışmamızın zayıf noktasını oluşturmaktadır.

\section{Sonuç}

Üreme çağındaki kadınların aile planlaması açısından eğitilmesi ve tercih edilecek olan korunma yöntemlerinin kadının içinde bulunduğu şartlara göre sağlık profesyonellerince belirlenmesi hem toplum sağlığı hem ülke ekonomisi hem de sosyolojik olarak önem arz etmektedir. Aile planlaması konusunda eğitimlerin uygun devlet kurumlarınca yaygınlaştırılması özellikle geçim sıkıntısı çeken bölgelerde hayati öneme sahiptir. Verilen bu eğitimlerle aile planlaması açısından halkta farkındalık oluşturmak etkin korunmayı artıracak ve isteğe balı kürtajları azaltacaktır.

\section{Kaynaklar}

1. Özdemir İ. Yıldırım U, Demirci F, Duras G, Yücel O. Düzce'de yaşayan 15-49 yaş grubu Evli Kadınların Kontraseptif Yöntemi Kullanma ve Kullanmama Nedenleri. Düzce Tıp Fakültesi Dergisi 2002; 4: 19-22.

2. Abbott J, Feldhaus KM, Houry D, Lowenstein SR. Emergency contraception: What do our patients know? Ann Emerg Med 2004; 43:376-381

3. World Health Organization. A tabulation of availabledata on the frequency an mortality of unsafeabortion. 2nd ed. Geneva: WHO devision of family health, maternal health and safemotherhoodprogramme; 1994. 
4. Demir Ü. Gebeliği önleyici yöntemlerin kullanımı ve bunlara etki eden sosyodemografik özelliklerin incelenmesi. Ege Üniversitesi Hemşirelik Yüksek Okulu Dergisi 1993; 8:31-34.

5. Reis N, Pasinlioğlu T. 2000 yılına doğru kürtaj aile planlaması yöntemi mi? Göztepe Tıp Dergisi.1997; 12(1): 37-39.

6. Sağsöz N, Bayram M, Kamacı M. Kırıkkale ili ve Çevresinde Kullanılan Kontraseptif Yöntemler. Türkiye Klinikleri Jinekoloji ve Obst. 2000; 10: 266-269.

7. Türkiye Nüfus ve Sağlık Araştırması, 2008 (Ekim 2009). Hacettepe Üniversitesi Nüfus Etütleri Enstitüsü, Sağlık Bakanlığı Ana Çocuk Sağlığı ve Aile Planlaması Genel Müdürlüğü, Başbakanlık Devlet Planlama Teşkilatı Müsteşarlığı ve TÜBİTAK, Ankara

8. Bozkurt N, Özkan S, Onan A, Korucuoğlu U, Aygün R, Himmetoğlu O. Distribution of contraceptive use in a Turkish population. Eur $\mathrm{J}$ Obstet Gynecol Reprod Biol 2007; 131: 52-56.

9. Pınar G, Öktem M, Algıer L, Doğan N, Zeyneloğlu H. Sağlı Personelinin Acil Kontrasepsiyona ilişkin bilgi görüş ve uygulamaları. J Turk Soc Obstet Gynecol 2005;2: 204-209.

10. Aylaz R, Yekeler B, Çam HH, Güneş G. Ebelerin Doğal Aile Planlaması Yöntemlerine İlişkin Bilgi
Tutum ve Davranışları. Fırat Sağlık Hizmetleri Dergisi 2009; 4: 151-158.

11. Dündar C, Süren C, Ordulu F. "Samsun İl Merkezinde 15- 49 Yaş Evli Kadınlarda Aile Planlaması Yöntemi Kullanma Durumu ve Etkileyen Faktörler", 8. Ulusal Halk Sağlığı Kongresi, Kongre Kitabı 2003;Cilt-1:163-166

12. Diker J, Erkoc A, Karataş N. Dr. İ. Şevki Atasagun Nevşehir Devlet Hastanesinde MR (Menstruel Regulasyon) yöntemi ile gebeliği sonlandırılan hastaların değerlendirilmesi. Sağlık ve Toplum 2003;13: 67-72.

13. Kavlak O, Atan ŞU, Saruhan A, Sevil U. Preventing and terminating unwanted pregnancies in Turkey. J Nurs Scholarsh 2006; 38:6-10.

14. Budak MŞ, Toğrul C, Balsak D, Sakar MN, Tahaoğlu AE, Akgöl S, Şentürk MB. İsteğe bağlı küretaj olan kadınların kontrasepsiyon ve küretaj nedenleri açısından değerlendirilmesi. JinekolojiObstetrik ve Neonatoloji Tıp Dergisi 2015;12: 106109

15. Gılıç E, Ceyhan O, Özer A. Niğde Doğumevi'nde Doğum Yapan Kadınların Aile Planlaması Konusundaki Bilgi Tutum ve Davranışları. Fırat Tıp Dergisi 2009; 14:237-241. 